\title{
The Effects of an Observational Intervention on the Acquisition of Reinforcing Properties of a Previously Neutral Stimulus
}

\author{
Jessica Singer-Dudek, R. Douglas Greer, \& Jeannine Schmelzkopf
}

\begin{abstract}
This study sought to further investigate the effects of an observational intervention for two participants on the reinforcing property of pieces of string. Pre-observational intervention data showed that the neutral stimuli (strings) did not function to reinforce two participants' responding to a performance task or learning three new skills that were not previously in their repertoires. The observational intervention involved the participants observing a peer confederate receive strings following responses that the participants could not see while they were deprived strings, regardless of whether their responses were correct or incorrect. Once the participants met criterion for terminating the intervention the same performance and learning tasks were again presented. The data showed that the strings now functioned to reinforce both performance and learning tasks. The results are discussed in terms of the utility of this procedure as an alternative to traditional stimulus-stimulus pairing procedures for conditioning neutral stimuli as reinforcers. Keyw ords: Observational learning, Conditioned reinforcement.
\end{abstract}

Humans can learn in one of two ways; through direct instruction, or through the observation of others (Greer, Singer-Dudek, \& Gautreaux, 2006). Observational learning is the process in which an individual learns a new response/environment relation (one that was not previously in his repertoire) as a result of the observation of another individual receiving contact with the contingencies of reinforcement, punishment, and corrections of incorrect responses (Catania, 2007; Gautreaux, 2005). Greer et al. (2006) state that there are three different functions of observational learning, including 1) the emission of previously acquired operants, 2) the acquisition of new operants through observation, and 3) the acquisition of conditioned reinforcers through observation. Although observational effects on learning new operants has a growing literature (Brody, Lahey, \& Combs, 1979; Egel, Richman, \& Koegel, 1981; Griffen, Wolery, \& Schuster, 1992; Goldstein \& Mousetis, 1989; Greer, et. al, 2006; McDonald, Dixon, \& Leblanc, 1986; Werts, Caldwell, \& Wolery, 1996) and the effects of observation on performance has been studied extensively (Bandura, 1986; Bandura, Adams, \& Beyer, 1977; Kazdin, 1973; Ollendick, Dailey, \& Shapiro, 1983), the acquisition of conditioned reinforcers through observation appears to be a new type of observational learning that has only very recently been identified (Greer \& Singer-Dudek, 2008; Greer, Singer-Dudek, Delgado, \& Oblak, 2007; Greer, Singer-Dudek, Longano, \& Zrinzo, in press; O’Rourke, 2006).

This new type of learning, identified as the acquisition of conditioned reinforcers by observation, can be defined as the acquisition of reinforcing properties of previously neutral stimuli as a function of observation (Greer et al., 2006; Greer \& Singer-Dudek, 2008). Conditioned reinforcement, which typically results from the stimulus-stimulus pairings of unconditioned or conditioned reinforcers with initially neutral stimuli that lead to the acquisition of reinforcing properties for the previously neutral stimuli (Catania, 2007; Donahoe \& Palmer, 2004; Dinsmoor, 2004; Kelleher \& Gollub, 1962) has been identified in the literature as important 
for increasing students' communities of reinforcers while decreasing stereotypy (Greer, Becker, Saxe, \& Mirabella, 1985; Nuzzolo-Gomez, Leonard, Ortiz, Rivera, \& Greer, 2002) and increasing the rate of learning for textual responding (Tsai \& Greer, 2006). However, stimulus-stimulus pairings can often be time consuming and, even then, are not always effective in conditioning new stimuli as reinforcers.

The use of peers has often been employed in conditioning new reinforcers for getting children to try new foods (Greer, McCorkle, \& Sales, 1998; Greer \& Sales, 1997) and inducing swallowing (Greer, Dorow, Williams, McCorkle, \& Asnes, 1991). Greer and Singer-Dudek (2008) reported an observational procedure that was effective in converting small plastic discs for five participants or pieces of string for one partic ipant from non-reinforcers to reinforcers for both learning and performance tasks. The present study was conducted in order to determine whether the results of this observational procedure (Greer \& Singer-Dudek, 2008) would replicate when the neutral stimuli used were strings, since there was only one participant in the Greer and SingerDudek study for whom strings were used. Could small pieces of string, which hold neither inherent value nor generalized reinforcement application, be conditioned as reinforcers using this procedure with other participants? In other words, would the results replicate? If so, what would that mean for developing stimuli that require no back up reinforcement or satiation potential for educational applications?

Specifically, we wanted to further examine the role of the experimenter in the present study. The same experimenter presented and consequated all performance, learning, and observational intervention triak for all participants for whom discs were used as the neutral stimuli but not to the participant for whom strings were the neutral stimuli in Greer and SingerDudek's (2008) study. For the one strings participant in their study, a less familiar experimenter, one who had no previous instructional experience with the participants, implemented the observational intervention. We wondered whether a less familiar experimenter would have any effect on the conditioning of the strings as a function of the observational intervention with our participants. We also wanted to examine further the effects of holding the number of postobservational intervention sessions constant (e.g., the same as had occurred during the preintervention condition) in the alternating phases of strings and food items. Finally, we wanted to examine the effects of the observational intervention procedure on the number of correct responses emitted for multiple learning tasks, as opposed to only one learning task, as was the case for the one participant for whom strings were conditioned in Greer and Singer-Dudek's (2008) study.

\section{Method}

\section{Participants}

The two participants in the study, Participants A and B, both attended a publicly funded private school for children with and without developmental delays. The students' existing academic, verbal, self-management, and problem solving repertoires, as well as their community of reinforcers were determined through criterion-referenced assessments, primarily using the Preschool Inventory of Repertoires for Kindergarten or PIRK (Greer \& McCorkle, 2003). Pieces of string, approximately 7.84 centimeters long (see Figure 1), did not function to reinforce the participants' responding for performance or learning tasks at the onset of the study. The participants were therefore chosen for this study because the strings did not function as conditioned reinforcers for them. 
Participant A was a four-year-old male diagnosed as a preschooler with a disability who functioned at a listener, speaker, emergent reader, and pre-writer level of verbal behavior at the time of the study (Greer \& Keohane, 2005). He could follow three-step verbal directions, textually respond to all of the upper and lowercase letters, tact pictures using the autoclitic phrase, "That's an item" as well as mand for items using the autoclitic phrase, "I want item please" (see Table 1).

Table 1: Description of Participant A According to her Verbal Capabilities, PIRK Repertoires, and Test Scores at the Time of the Study

\begin{tabular}{|c|c|c|}
\hline Verbal Capabilities & PIRK Objectives & Test Scores \\
\hline $\begin{array}{l}\text {-Teacher Presence Results } \\
\text { in Instuctional Control } \\
\text {-Conditioned reinforcement } \\
\text { for voices. } \\
\text {-Conditioned } \\
\text { Reinforcement for Visual } \\
\text { Stimuli } \\
\text {-Capacity for sameness } \\
\text { across senses } \\
\text {-Matching 2D and 3D } \\
\text { objects } \\
\text {-Generalized Imitation } \\
\text {-Listener Literacy } \\
\text {-Auditory Matching of } \\
\text { words } \\
\text {-Parroting } \\
\text {-Echoic to Mand/Tact } \\
\text {-Independent Mands/Tacts } \\
\text {-Transformation of EO } \\
\text { across mands and tacts }\end{array}$ & $\begin{array}{l}\text { Academic Equivalence } \\
\text { Relations: } \\
\text {-Matching } \\
\text { Reading/Writing Sameness to } \\
\text { Equivalency } \\
\text {-Discriminates between words } \\
\text { and pics. } \\
\text { Numeric Sameness to } \\
\text { Equivalency: } \\
\text {-Matches/Points/ } \\
\text { Texually Responds to Numbers } \\
\text { 1-100. } \\
\text { Reading } \\
\text {-Textually Responds to dolch } \\
\text { words } \\
\text { Number Skills } \\
\text {-Intraverbal Counting } \\
\text {-General Knowledge } \\
\text {-Colors } \\
\text {-Gender } \\
\text {-Personal Info } \\
\text {-Weather/Seasons } \\
\text {-Intraverbal Responses } \\
\text {-Affirmation/ } \\
\text { Negation for Tacts/Mands } \\
\text {-Why?'s } \\
\text {-Function of Object } \\
\text { - What do you when ?'s } \\
\text { Worksheet Skills } \\
\text {-Draws line between } \\
\text { Listener Behavior } \\
\text {-Sit still } \\
\text {-Look at me } \\
\text {-Imitates non-verbal gestures } \\
\text {-Follows vocal verbal } \\
\text { instructions in 1:1 and group } \\
\text { setting } \\
\text {-Points to body parts }\end{array}$ & $\begin{array}{l}\text { Preschool Language Scale } \\
\text { (PLS): } \\
\text { - Auditory Comprehension: } \\
\text { SS75 } \\
\text {-Expressive } \\
\text { Communication: } \\
\text { SS71 }\end{array}$ \\
\hline
\end{tabular}


Participant B was a three-year-old female diagnosed as a preschooler with a disability who functioned at a listener, speaker, pre-reader, emergent writer level of verbal behavior at the time of the study (Greer \& Keohane, 2005). She could follow one-step vocal directions, textually respond to all the upper and lowercase letters, tact pictures and objects using the autoclitic phrase, "That's an item" as well as mand for items using the autoclitic phrase, "I want item please" (see Table 2).

Table 2: Description of Participant B According to his Verbal Capabilities, PIRK Repertoires, and Test Scores at the Time of the Study

\begin{tabular}{|c|c|c|}
\hline Verbal Capabilities & PIRK Objectives & Test Scores \\
\hline $\begin{array}{l}\text {-Teacher Presence Results } \\
\text { in Instructional Control } \\
\text {-Conditioned } \\
\text { Reinforcement for Visual } \\
\text { Stimuli } \\
\text {-Capacity for sameness } \\
\text { across senses } \\
\text {-Matching 2D and 3D } \\
\text { objects } \\
\text {-Generalized Imitation } \\
\text {-Listener Literacy } \\
\text {-Auditory Matching of } \\
\text { words } \\
\text {-Parroting } \\
\text {-Echoic to Mand/Tact } \\
\text {-Independent Mands/Tacts } \\
\text {-Transformation of EO } \\
\text { across mands and tacts }\end{array}$ & $\begin{array}{l}\text { Academic Equivalence } \\
\text { Relations: } \\
\text {-Matching } \\
\text { Reading/Writing Sameness to } \\
\text { Equivalency: } \\
\text {-Discriminates between words } \\
\text { and pics. } \\
\text {-Writes dictated letters } \\
\text { Numeric Sameness to } \\
\text { Equivalency: } \\
\text {-Matches/Points/ } \\
\text { Texually Responds to Numbers } \\
\text { 1-100. } \\
\text { Reading } \\
\text {-Textually Responds to dolch } \\
\text { words } \\
\text { Number Skills } \\
\text {-Tells Next Number } \\
\text {-General Knowledge } \\
\text {-Colors } \\
\text {-Gender } \\
\text {-Personal Info } \\
\text {-Intraverbal Responses } \\
\text {-Why ?'s } \\
\text {-Function of Object } \\
\text { - What do you when ?'s } \\
\text { Listener Behavior } \\
\text {-Sit still } \\
\text {-Look at me } \\
\text {-Imitates non-verbal gestures } \\
\text {-Follows vocal verbal } \\
\text { instructions in 1:1 and group } \\
\text { setting } \\
\text {-Points to body parts }\end{array}$ & $\begin{array}{l}\text { Preschool Language Scale } \\
\text { (PLS): } \\
\text {-Auditory Comprehension: } \\
\text { SS61 } \\
\text {-Expressive } \\
\text { Communication: } \\
\text { SS74 }\end{array}$ \\
\hline
\end{tabular}


In addition to the two participants, two other children served as peer confederates. Both of the confederates were classmates of the two participants; Confederate 1 was paired with Participant A and Confederate 2 was paired with Participant B. Confederate 1 was a four-year-old female at the time of the study and Confederate 2 was a four-year-old male at the time of the study, both of whom functioned at a listener, speaker, emergent reader/writer level of verbal behavior. The confederates were chosen for this study because, although they were in the same classroom, they had little contact with the participants during play or other social activities.

\section{Materials and Setting}

The participants in the study attended a publicly funded privately run preschool for children with and without disabilities, including developmental delays, speech/language delays, and behavioral problems. The school was located outside of a major metropolitan area and used the Comprehensive Application of Behavior Analysis to Schooling $\left(\mathrm{CABAS}^{\circledR}\right)$ model of instruction (Greer, Keohane, \& Healy, 2002). The students were taught all of their curricula through teaching as applied behavior analysis. Thus, the participants in this study were accustomed to receiving individualized and small-group instruction that included frequent positive reinforcement in the form of adult approvals and in most cases, tokens, which were generalized reinforcers that could be later exchanged for a host of backup reinforcers that were available in the classroom or in the school, such as food items, preferred toys, and time on the computer. The participants in this study, however, did not have a history of generalized reinforcers and were not familiar with the exchange system that was in place for other students in the classroom, even though they had been present when their peers received and exchanged generalized reinforcers in the form of tokens. In other words, the participants had not acquired tokens as conditioned reinforcers as a function of observation of their peers receiving and exchanging tokens.

During all conditions, the experiment was conducted in the participants' classroom. Each child sat in a child-sized chair at a child-sized table along with the experimenter. During the preand post-observational intervention procedures one experimenter functioned as the data collector. Both participants had an instructional history with the experimenter, so she was familiar to them. During the observational intervention, a different experimenter delivered the antecede nts to both the participant and the peer confederate and delivered the strings to the peer confederate. This was an individual who visited the classroom frequently but did not have an instructional history with either participant. Hence, the experimenter who delivered the strings was not as familiar as the experimenter who conducted the pre- and post-intervention performance and learning trials. We wondered whether a less familiar experimenter, with whom the participants had no prior instructional history, would play any role in the participants' responding during the observational intervention, and hence affect the conditioning of the strings as reinforcers, so this was one variable we controlled for. The independent observer, when present, also sat at the table.

While the study was conducted other students received either group or individual instruction at adjacent tables. The students in the classroom were accustomed to having additional individuals come into and work in their classroom, so this did not pose a distraction. Additionally, the participants in this study were also accustomed to working separately in the classroom while other observers were present, so they were not likely to demonstrate any reactivity to the independent observers.

The stimuli used in the experiment included pieces of string, food items (e.g., cookies), a cup, a timer, and instructional stimuli. The pieces of string were all purple in color and were approximately $7.84 \mathrm{~cm}$ long (see Figure 1). The cup, which was used as a receptacle for the 
strings and food items, was transparent and was approximately $15 \mathrm{~cm}$ high and $8.5 \mathrm{~cm}$ wide. During the performance task conditions the experimenter used a timer that counted up from " 0 " in both minutes and seconds. The instructional stimuli used in the study for the performance tasks, learning tasks, and observational conditioning procedure included pictures or words for both participants. See Table 3 for a complete list of the stimuli used for each participant.

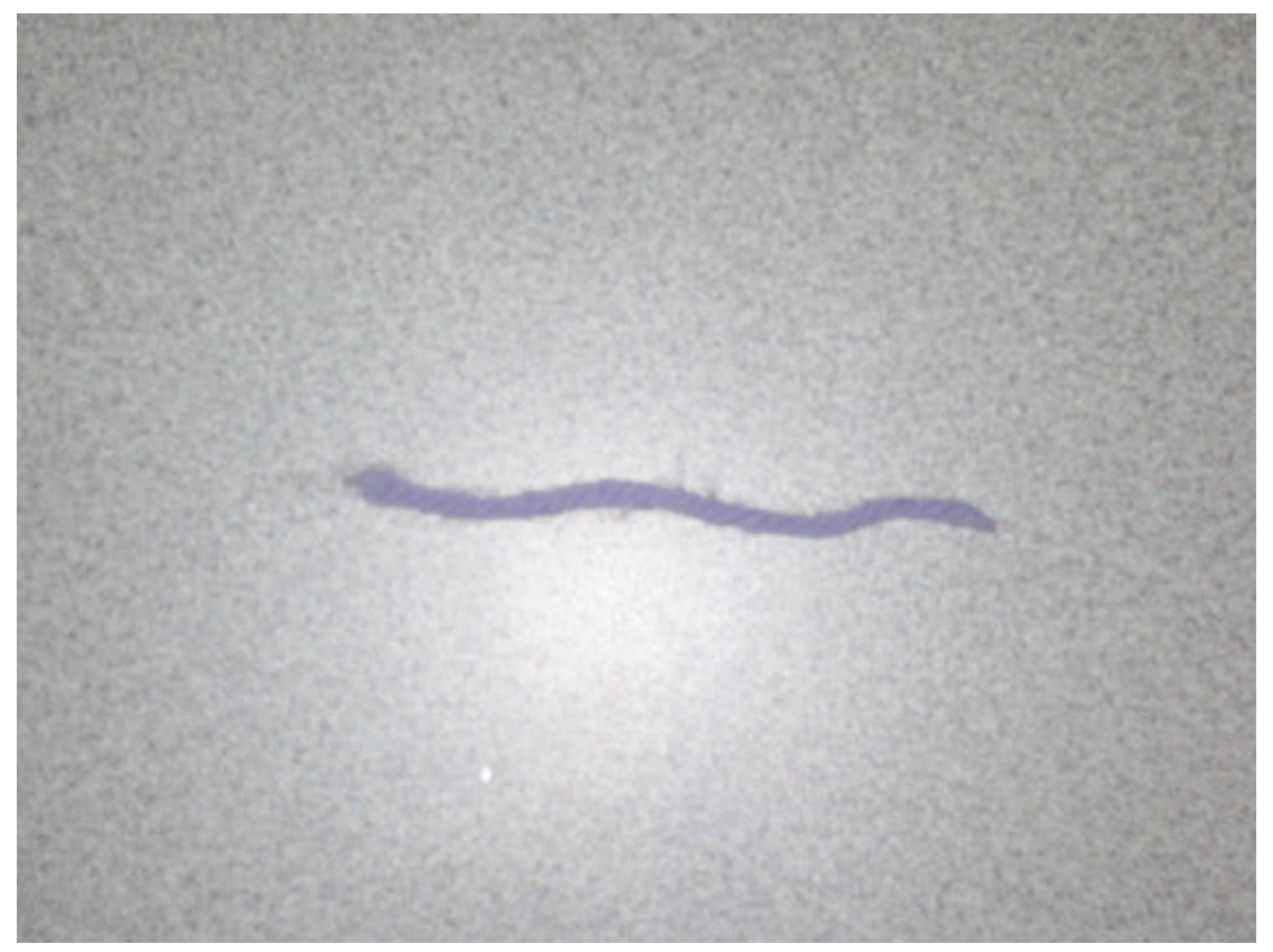

Figure 1

\section{Design and Procedure}

A pre-post intervention design with three conditions was implemented across two types of responses, performance and learning tasks, in order to determine the acquired reinforcement effects of initially neutral stimuli (small pieces of string) prior to and following an observational intervention procedure. The conditions consisted of 1) a counterbalanced pre- and postintervention $\mathrm{ABAB}$ (Participant A) or BABA (Participant B) reversal design for one performance task in order to determine the reinforcing effects of strings compared to established reinforcers (food items), 2) the observational conditioning intervention during which participants observed peer confederates receive the neutral stimuli but were denied those same stimuli, and 3) pre-and post-intervention tests for three learning tasks that were not initially in the participants' repertoires. 


\section{Pre-Observational Intervention Procedures}

Performance Tasks. In the pre-experimental condition, each participant's responding to a performance task under two conditions (food items and strings delivered as consequences for correct responses) was measured. Each session consisted of 10 timed trials and lasted no more than 2 minutes. Between 2 and 4 sessions of the performance task were conducted each day. For both participants the performance tasks used were chosen from a set of repertoires that were previously determined to have been mastered. They were skills that would be easily performed, but that the participants would not perform without prosthetic reinforcement. The performance tasks for each participant are listed in Table 3.

Table 3

Description of the Performance and Learning Tasks for Participants A and B before, after, and during the Observational Intervention

\begin{tabular}{|l|l|l|l|l|l|}
\hline & $\begin{array}{l}\text { Performance } \\
\text { Task }\end{array}$ & $\begin{array}{l}\text { Learning Task } \\
1\end{array}$ & $\begin{array}{l}\text { Learning Task } \\
2\end{array}$ & $\begin{array}{l}\text { Learning Task } \\
3\end{array}$ & $\begin{array}{l}\text { Observational } \\
\text { Intervention } \\
\text { Task }\end{array}$ \\
\hline Participant A & $\begin{array}{l}\text { Matching } \\
\text { Pictures: } \\
\text { Paint brush, } \\
\text { computer, } \\
\text { radio, hat, } \\
\text { paper, books, } \\
\& \text { brush. }\end{array}$ & $\begin{array}{l}\text { Pointing to } \\
\text { Sight Words: } \\
\text { Made, Pick, } \\
\text { Start }\end{array}$ & $\begin{array}{l}\text { Textually } \\
\text { Responding to } \\
\text { Sight Words: } \\
\text { Only, Made, } \\
\text { Work }\end{array}$ & $\begin{array}{l}\text { Intraverbal } \\
\text { Counting: } \\
75-80\end{array}$ & $\begin{array}{l}\text { Matching } \\
\text { Numbers: } \\
1-10\end{array}$ \\
\hline Participant B & $\begin{array}{l}\text { Matching } \\
\text { Pictures: } \\
\text { Paint brush, } \\
\text { computer, } \\
\text { radio, hat, } \\
\text { paper, books, } \\
\& \text { brush. }\end{array}$ & $\begin{array}{l}\text { Pointing to } \\
\text { Sight Words: } \\
\text { Work, Only }\end{array}$ & $\begin{array}{l}\text { Textually } \\
\text { Responding to } \\
\text { Sight Words: } \\
\text { Draw, Round }\end{array}$ & $\begin{array}{l}\text { Tacting } \\
\text { Pictures of } \\
\text { Dogs: } \\
\text { Bijon, German } \\
\text { Shepard, } \\
\text { Cocker } \\
\text { Spaniel }\end{array}$ & $\begin{array}{l}\text { Numbers: } \\
1-10\end{array}$ \\
\hline
\end{tabular}

For both participants, this task was a matching task in which the participants were given a picture of a common object while an identical picture and one non-exemplar were placed on the table in front of each. The experimenter delivered the vocal antecedent, "Match __," and the participant was to match the stimulus in hand to the identical one on the table. Correct responses, in which the participant placed the stimulus on the correct exemplar within 3 seconds, were followed by the delivery of either established reinforcers (food items) in " $A$ " conditions or strings (neutral stimuli) in "B" conditions into translucent plastic cups placed on the table in front of the participants in their direct line of sight, but just out of reach. At no time did either of the participants receive vocal praise of any other form of approval from the experimenter. Incorrect responses or failure to respond resulted in the experimenter removing the stimuli, waiting $3 \mathrm{~s}$, and presenting a new trial. Following the completion of a 10-trial session, the participant was allowed to consume all of the edibles in the cup during the food item conditions; the participant was not, however, allowed access to the strings following the completion of the neutral conditions. The order of presentations of preferred items and neutral conditions for Participant A was the food items (A), the strings (B), a return to the food items (A), and then a return to the strings (B) and 
for Participant B was the strings (B), the food items (A), a return to the strings (B), and a return to the food items (A). During the pre-intervention performance task, sessions were repeated for each condition until the data showed stable responding. This meant that during the neutral stimulus (strings) conditions correct responses were at or near 0 while incorrect responses were high, and during the food items condition correct responses were high while incorrect responses were at or near 0 for at least four data paths.

Learning Tasks. In addition, prior to the observational conditioning procedure, each participant received repeated instruction in learning three new skills, or learning tasks (please see Table 3 for a list of the learning tasks chosen for each participant). During each learning task, the experimenter presented the antecedent and the participant responded. Following a correct response the experimenter delivered a piece of string by placing it in the translucent cup. Following an incorrect response, no strings were delivered; instead, a correction procedure was presented (i.e. the experimenter re-presented the antecedent, modeled the correct response, and the participant repeated the correct response). The participants did not receive vocal praise from the experimenter at any time and, unlike the performance task, at no point during the learning tasks did the experimenter deliver any preferred food items. No more than 1 session of each learning task was conducted each day and each session took between 2 and 5 minutes. Sessions were continued for each pre-observational intervention learning task until the data showed stable responding (no ascending trend or a descending trend demonstrating extinction of correct responses) for four or more data paths.

\section{Observational Intervention Procedures}

During the observational conditioning procedure, a partition was placed between the participant and his or her peer such that the children could not observe the accuracy of each other's responses; however, they could observe each other's cup. Although the children could not observe the accuracy of each other's responses, they could observe each other's head and shoulders and whether or not their peer received a piece of string in the cup following each trial. The experimenter (different from the one who presented and consequated the performance and learning tasks) presented each child with a second performance task (i.e. a task that both had previously mastered, see Table 3). These 10 trial sessions were repeated until the participant met a pre-determined criterion. No more than 2 sessions of the observational intervention were conducted each day and each lasted approximately 2 minutes. The criterion used in Greer and Singer-Dudek's (2008) study was 2 consecutive sessions of vocal or non-vocal mands. We noticed that 3 of the 6 participants in Greer and Singer-Dudek's study also emitted very low numbers of correct responses at the end of the intervention condition, thereby demonstrating extinction of correct responding. Because the participants in their study all required at least 10 sessions of the intervention before they met the criterion, we decided to run a minimum of 8 sessions, at which time a decision was made to continue if a) the participant's correct responses had begun to demonstrate a descending trend or extinction of correct responding and b) had not emitted any mands for the strings, either vocal or non-vocal. If one or the other did not occur then a decision was made to continue. Cessation of the observational intervention was decided upon on an individual basis (see Results and Discussion below). The numbers of non-vocal (Participant A) and vocal (Participant B) mands for the strings that were emitted by the participants were also measured during the observational intervention (see Figure 5).

\section{Post-Observational Intervention Procedures}

Following the completion of the observational intervention, the participants were reintroduced to the same performance task presented during the pre-observational intervention. 
Once again the participants were presented with the strings or preferred food items for correct responses, depending on the condition, and the experimenter ignored incorrect responses as she had done in the pre-observational experimental tests. The order of presentation of the strings conditions and food items conditions were the same for Participants A and B as they had been in the pre-observational intervention condition. As for the one strings participant in Greer and Singer-Dudek's (2008) study, the same number of sessions was presented for each condition following the observational intervention as had been presented in each condition prior to the intervention in order to demonstrate sustained reinforcement effects of the strings as compared to the food items in alternating conditions.

Both of the participants were also re-introduced to the learning tasks they had not learned when strings were delivered following correct responses in the pre-observational intervention procedure. Once again, strings were delivered for correct responses and a correction procedure was presented for incorrect responses. No vocal praise or adult approval was delivered for correct responses. Sessions were continued for the learning tasks following the observational intervention until the data showed stable responding (ascending trends or higher levels of correct responses than prior to the intervention) or the participants met mastery criteria.

\section{Data Collection}

Data were collected for the performance task in timed 10-trial sessions, the learning tasks in 20-trial sessions that were not timed, and the observational intervention in 10-trial sessions, during which correct and incorrect responses were recorded by the experimenter as a plus, "+" or a minus, "-" respectively. For the performance tasks, the experimenter began the timer when the antecedent for the first trial was delivered and stopped the timer following the participant's response for the $10^{\text {th }}$ trial, and the elapsed time was then written on the data collection form and used to calculate the rate. The rate correct/incorrect was calculated by dividing the number correct/incorrect by the total amount of time elapsed from the first antecedent presented to the consequence given for the final trial. The rate, or number correct and incorrect per minute, was then graphed following the completion of the performance task session. The number of correct responses was graphed following the completion of a learning task session and each session of the observational intervention.

\section{Interobserver Agreement}

The interobserver agreement scores were calculated by dividing the total number of paired observer agreements by the total numbers of agreements plus disagreements and then multiplying that number by $100 \%$. Interobserver agreement was conducted for the performance tasks for $42 \%$ of the sessions for Participant A and $40 \%$ of the sessions for Participant B and was $100 \%$ across all participants. Interobserver agreement was conducted for the learning tasks for $32 \%$ of the sessions across Participants A and B and was 100\%. Interobserver agreement was conducted for $86 \%$ of the observational conditioning procedure sessions for Participants A and B and was $100 \%$.

\section{Results}

The results showed that prior to the observational intervention, the strings functioned as neutral stimuli in that they did not reinforce the participant's responding to either performance or learning (acquisition) tasks. Following the observational intervention, the strings functioned to reinforce both performance tasks and the three learning tasks. 


\section{Pre-Observational Intervention}

Performance Tasks. Figure 2 shows the rate of correct and incorrect responses to the performance task during both food items (A) and strings (B) conditions for Participants A and B. For the performance task in the pre-observational intervention for Participant A, in the first food items condition the mean rate of correct responses was 6.27 with a range from 6.1 to 6.7 and a mean of 0 incorrect responses. In the first strings (neutral stimuli) condition the mean rate of correct responses was 6.18 with a range from 0 to 7.1 and the mean rate of incorrect responses was 3.3 with a range from 0 to 8.2. In the return to food items condition the mean rate of correct responses was 5.62 with a range from 5.5 to 6.25 and a mean of 0 incorrect responses. In the return to strings condition the mean rate of correct responses was 1.9 with a range from 0 to 3.7 and the mean rate of incorrect responses was 3.9 with a range from .8 to 8.26.

In the pre-observational intervention for Participant $\mathrm{B}$, in the first strings condition the mean rate of correct responses was 1.4 with a range from 0 to 3.9 and the mean rate of incorrect responses was 3.4 with a range from .91 to 7.4. In the first food items condition the mean rate of correct responses was 4.5 with a range from 3.9 to 5.05 and the mean rate of incorrect responses was .2 with a range from 0 to .89 . In the return to the strings phase the mean rate of correct responses was 1.9 with a range from 0 to 4.3 and the mean rate of incorrect responses was 3.8 with a range from 1.1 to 8.1. In the return to the food items condition the mean rate of correct responses was 4.4 with a range from 2.41 to 4.9 and the mean rate of incorrect responses was .52 with a range from 0 to 1.6.
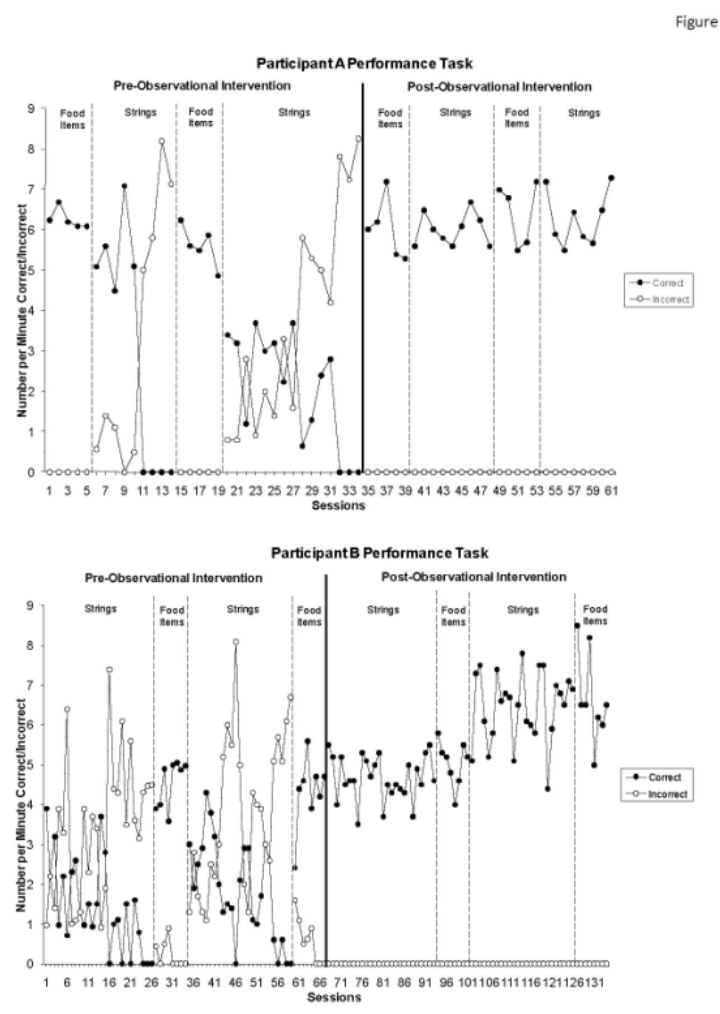
Learning Tasks. Figure 3 shows the numbers of correct responses to the three learning tasks during the pre- and post-observational intervention conditions for Participant A. In the preobservational intervention, for the first learning task for Participant A, pointing to sight words, the mean number of correct responses was 2 with a range from 0 to 6 . The mean number of correct responses for the second learning task, textually responding to sight words, was 5.3 with a range from 2 to 9 . The mean number of correct responses for the third learning task, intraverbal counting, was 2 with a range from 1 to 3.

[Insert Figure 3 about here]
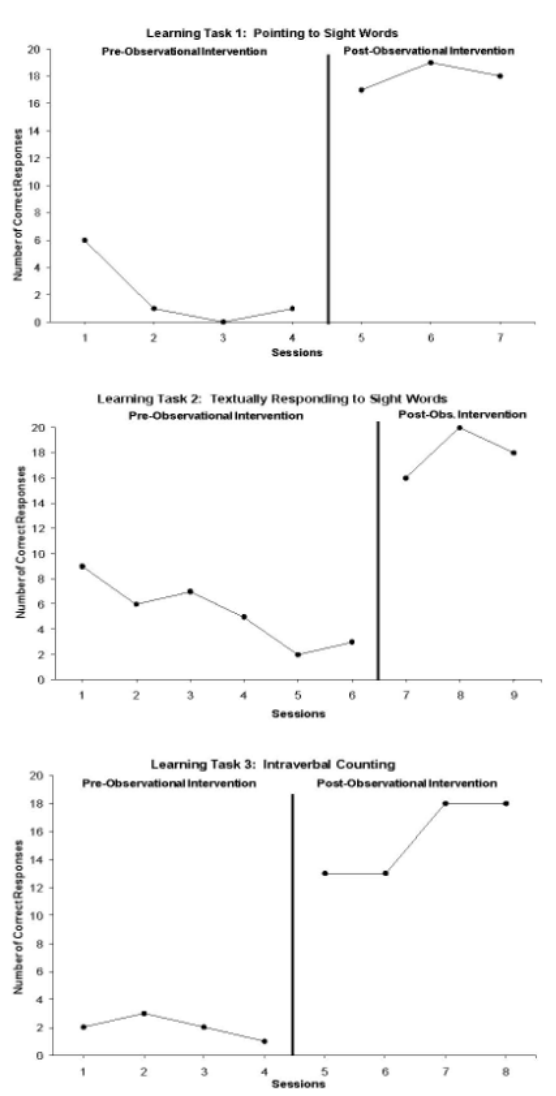

Figure 4 shows the numbers of correct responses to the three learning tasks during the pre- and post-observational intervention conditions for Participant B. For the first learning task for Participant B, pointing to sight words, the mean number of correct responses was 3.3 with a range from 1 to 6 . For the second learning task, textually responding to sight words, the mean number of correct responses was 1 with a range from 0 to 2, and for the third learning task, tacting pictures of dogs, the mean number of correct responses was 0 for Participant B. 
Figure 4.
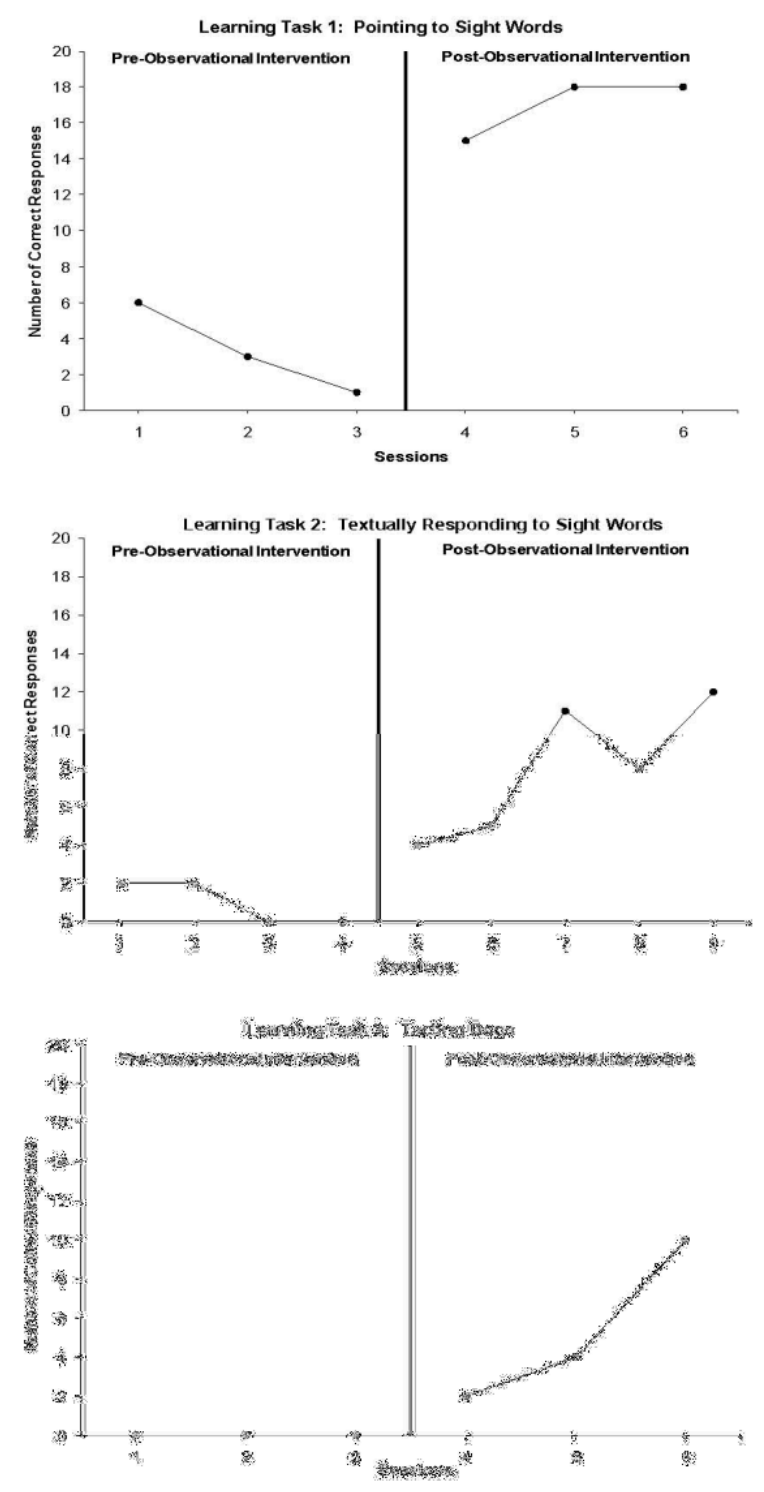

The Observational Intervention. Figure 5 shows the numbers of correct responses and the numbers of non-vocal (Participant A) and vocal mands (Participant B) emitted during the observational intervention for Participants A and B. For Participant A, during the observational intervention, correct responses had begun to demonstrate a descending trend and although mands had been high during previous sessions, no mands were emitted during the $8^{\text {th }}$ session, so a decision was made to continue. In the $9^{\text {th }}$ session, correct responding increased, as did mands, so a 
decision was made to continue. The $10^{\text {th }}$ session resulted in a decrease in correct responding and an increase in non-vocal mands, so the decision was made to stop the intervention following two consecutive sessions of mands with no further decrease in correct responding. For Participant B, correct responses had begun to decrease in the $8^{\text {th }}$ session and there had been 2 consecutive sessions during which mands were emitted, but we wanted to see whether correct responses would further decrease, so the decision was made to continue. The $9^{\text {th }}$ session resulted in an increase again of correct responses, with non-vocal mands still occurring, so the decision was made to stop the intervention.
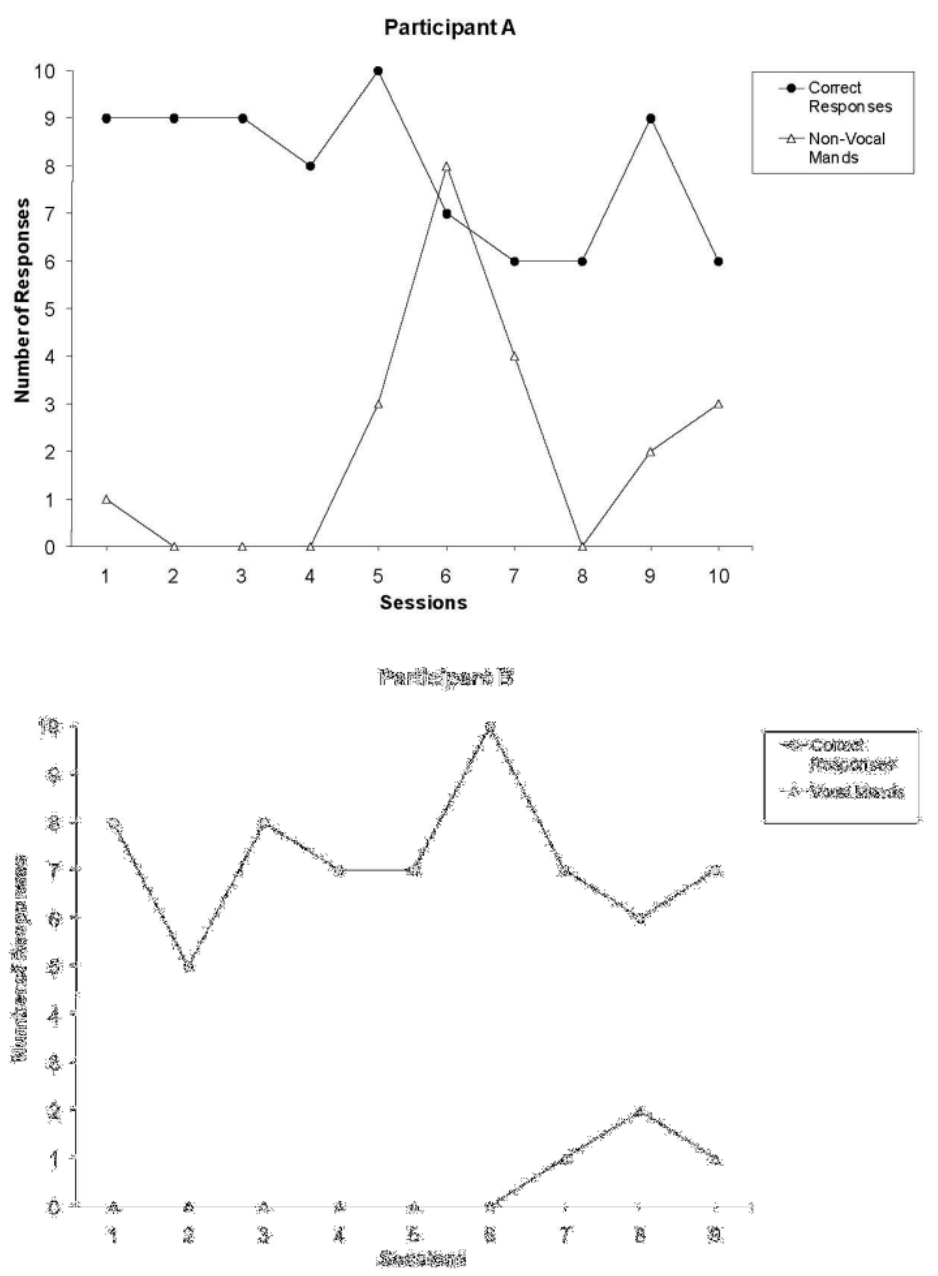


\section{Post-Observational Intervention}

Performance Tasks. In the post-observational intervention for the performance task, Participant A emitted a mean of 6 correct responses with a range from 5.3 to 7.2 and a mean of 0 incorrect responses in the first food items condition. In the first strings condition, the mean rate of correct responses was 6 with a range from 5.6 to 6.7 and a mean of 0 incorrect responses. In the return to the food items condition, the mean rate of correct responses was 6.4 with a range from 5.5 to 7.2 with a mean of 0 incorrect responses. In the return to the strings condition the mean rate of correct responses was 6.6 with a range from 5.5 to 7.2 with a mean of .05 incorrect responses with a range from 0 to .8 (see Figure 2).

In the post-observational intervention for the performance task, in the first strings condition Participant B emitted a mean rate of 4.7 correct responses with a range from 3.5 to 5.5 and a mean of 0 incorrect responses. In the return to the food items condition, the mean rate of correct responses was 5.1 with a range from 4 to 5.8 and the mean of incorrect responses was 0 . In the return to the strings condition, the mean rate of correct responses was 6.5 with a range from 4.4 to 7.8 and the mean of incorrect responses was 0 . In the return to the food items condition, the mean rate of correct responses was 6.7 with a range from 5 to 8.5 and the mean of incorrect responses was 0 (see Figure 2).

Learning Tasks. In the post-observational intervention, for the first learning task for Participant A, pointing to sight words, the mean number of correct responses was 18 with a range from 17 to 19. The participant met the pre-determined criterion of at least $90 \%$ correct responding across two sessions, after only three sessions. For the second learning task, textually responding to sight words, the mean number of correct responses was 18 with a range from 16 to 20 and the participant met the pre-determined criterion after three sessions. For the third learning task, intraverbal counting, the participant emitted a mean of 16 correct responses with a range from 13 to 18 correct responses. The participant met the pre-determined criteria after four sessions (see Figure 3).

For the first learning task in the post-observational intervention for Participant B, pointing to sight words, the mean number of correct responses was 17 with a range from 15 to 18 , and the participant met the pre-determined criterion after three sessions. For the second learning task, textually responding to sight words, Participant B emitted a mean number of 8 correct responses with a range from 4 to 12. For the third learning task, tacting dogs, Participant B emitted a mean number of 5.3 correct responses with a range from 2 to 10 (see Figure 4).

The results showed that neutral stimuli, which did not function to reinforce the two participants' correct responding to learning or performance tasks prior to the observational intervention, acquired reinforcing properties in that they increased correct and decreased incorrect responding for both types of tasks following the observational intervention.

\section{Discussion}

The results in the present study are consistent with those found in the Greer and SingerDudek (2008) study. The data reported herein demonstrated that pieces of string could be conditioned as reinforcers through observation for performance and learning new operants for an additional two participants to the one identified in the 2008 study. 
In the present study, the role of the experimenter was examined, in that the observational intervention sessions were conducted by an experimenter with whom the neither of the participants had an instructional history, which was consistent with the one participant for whom strings were used as the neutral stimuli in the Greer and Singer-Dudek (2008) study. The participants' responding during the observational intervention did not demonstrate extinction effects, although Participant A's correct responses did initially demonstrate a descending trend, despite the lack of reinforcement during the procedure. This is consistent with the results from the strings participant in Greer and Singer-Dudek's study. It is important to note that the participants for whom the experimenter was the same in all conditions (pre- and post-observational intervention tests of the performance and learning tasks and the intervention itself) in their study had all demonstrated very low numbers of correct responses at some point during the intervention. When the experimenter was an unfamiliar adult with no history of presenting instruction to either participant, the participants' correct responding during the observational conditioning procedure did not demonstrate significant decreases. The cause of the absence of an extinction curve is not completely clear. Further research investigating the role of the experimenter is needed, perhaps involving a study in which the experimenter is completely removed from the observational intervention (e.g., whereby an automated device delivers the stimuli) in order to further examine this phenomenon. Nevertheless, the data in the postobservational intervention tests showed that although both participants emitted high numbers of correct responses during the observational conditioning procedure, the procedure was effective in conditioning the strings as reinforcers for both performance and learning tasks.

Additionally, similar to the conditions for the participant for whom strings were conditioned in the Greer and Singer-Dudek (2008) study, the number of post-observational intervention sessions in the performance task was held constant with those presented during the pre-observational intervention. This was done in order to determine whether extinction effects would be seen for the strings as the sessions continued. In other words, in Greer and SingerDudek's study, the post-observational intervention conditions were rapidly alternated, sometimes after a single session. We wanted to see what would happen if the participants were exposed to the same number of sessions as it took for the performance to demonstrate extinction effects in the pre-intervention conditions. Correct responses in the post-observational intervention conditions where strings were delivered following correct responses remained high, while incorrect responses remained at zero in all but one session (Participant A). Therefore, even after repeated sessions in which strings were delivered contingent upon correct responding no extinction effects observed, demonstrating that the strings now functioned to reinforce performance.

Furthermore, the present study was conducted to examine the effects of the observational intervention procedure on multiple learning tasks for the two participants, as opposed to the sole learning task that was used for the one strings participant in the Greer and Singer-Dudek (2008) study. For Participant A, following the observational intervention procedure, the number of correct responses across all three learning tasks increased significantly and the participant met the pre-determined mastery criterion for all of the tasks presented. Similar results were found for Participant B for the first learning task presented, however although the number of correct responses increased for the remaining two tasks, they did not increase as drastically as for Participant A. This could possibly be due to a slower rate of learning across most programs for Participant B, and perhaps if more sessions had been conducted for these learning tasks the number of correct responses would have continued to increase. This is also plausible given that the data for the second and third learning tasks for Participant B demonstrated ascending trends. Unfortunately the participant ceased to attend the school at that point in the study and the 
experimenter was not able to continue to conduct sessions for the remaining two learning tasks during the post-observational intervention.

The effects that were seen across all three of the learning tasks for Participant A and the first learning task for Participant B were also consistent with those in Greer and Singer-Dudek's (2008) study. For all four of these tasks, the number of correct responses emitted in the first session of the post-observational intervention condition significantly increased from the last session of the pre-observational intervention (e.g., from 1 to 17). This suggests that perhaps the participants had already learned the task during the pre-observational intervention (identified as latent learning by Greer and Singer-Dudek), but were not emitting correct responses due to a lack of reinforcement. In the post-observational intervention sessions, the sudden increase in the number of correct responses to criterion or near criterion levels suggest that they began to respond correctly to a learned task because reinforcement was now being provided (i.e. the strings had now acquired reinforcing properties).

The present study was a direct replication of the procedures for Participant F, for whom strings were conditioned as reinforcers, in Greer and Singer-Dudek's (2008) study. The data in the present study were consistent with those found in Greer and Singer-Dudek's experiment, suggesting that pieces of string, which hold no inherent value, could be conditioned as reinforcers through observation, with no opportunities for exchange for backup reinforcers ever introduced. The implications of this study suggest that if this observational intervention procedure has been successful in conditioning stimuli which have no importance to the participants' education per se, it could also have utility in conditioning stimuli as reinforcers that will ultimately have greater significance, such as books (Greer, Singer-Dudek, Delgado, \& Oblak, 2007), math (O'Rourke, 2006), or teacher praise (Greer, Singer-Dudek, Longano, \& Zrinzo, in press).

\section{References}

Bandura, A. (1986). Social foundations of thought and action. Englewood Cliffs, NJ: PrenticeHall.

Bandura, A., Adams, N. E., \& Beyer, J. (1977). Cognitive processes mediating behavioral change. Journal of Personality and Social Psychology, 35, 125-139.

Brody, G. H., Lahey, B. B., \& Combs, M. L. (1978). Effects of intermittent modeling on observational learning. Journal of Applied Behavior Analysis, 11, 87-90.

Catania, A. C. (2007). Learning (interim $4^{\text {th }}$ ed.). Cornwall-on-Hudson, NY: Sloan Publishing.

Dinsmoor, J.A. (2004). The etymology of basic concepts in the experimental analysis of behavior. Journal of the Experimental Analysis of Behavior, 82, 311-316.

Donahoe, J.W. \& Palmer, D.C. (2004). Learning and Complex Behavior. Richmond, MA: Ledgetop Publishing.

Egel, A. L., Richman, G. S., \& Koegel R. L. (1981). Normal peer models and autistic children's learning. Journal of Applied Behavior Analysis, 14, 3-12. 
Gautreaux, G. G. (2005). The effects of monitoring training on the acquisition of an observational learning repertoire under peer tutoring conditions, generalization and collateral effects (Doctoral dissertation, Columbia University, 2005). Dissertation Abstracts International, 66, 1713A. [Proquest AAT 3174795].

Goldstein, H., \& Mousetis, L. (1989). Generalized language learning by children with severe mental retardation: Effects of peers' expressive modeling. Journal of Applied Behavior Analysis, 22, 245-259.

Greer, R. D., Becker, B. J., Saxe, C. D., \& Mirabella, R. F. (1985). Conditioning histories and setting stimuli controlling engagement in stereotypy or toy play. Analysis and Intervention in Developmental Disabilities, 5, 269-284.

Greer, R. D., Dorow, L., Williams, G., McCorkle, N., \& Asnes, R. (1991). Peer-mediated procedures to induce swallowing and food acceptance in young children. Journal of Applied Behavior Analysis, 24, 783-790.

Greer, R.D., \& Keohane, D. (2005). The evolution of verbal behavior in children. Behavioral Developmental Bulletin, 1, 31-46.

Greer, R.D., Keohane, D.D., \& Healy, O. (2002). Quality and Comprehensive Applications of Behavior Analysis to Schooling. The Behavior Analyst Today, 3, 120-133.

Greer, R.D. \& McCorkle, N. (2003). CABAS ${ }^{\circledR}$ international curriculum and inventory of repertoires from pre-school through kindergarten. Yonkers, NY: CABAS ${ }^{\circledR}$ and the Fred S. Keller School.

Greer, R. D., McCorkle, N. P., \& Sales, R. D. (1998, June). Conditioned reinforcement as a function of peer contingencies with pre-school children. Paper presented at the Annual International Conference of the Association for Behavior Analysis, Washington, DC.

Greer, R. D., \& Sales, C. D. (1997, May). Peer effects on the conditioning of a generalized reinforcer and food choices. Paper presented at the Annual International Conference of the Association for Behavior Analysis, Chicago, IL.

Greer, R.D., \& Singer-Dudek, J. (2008). The emergence of conditioned reinforcement from observation. Journal of the Experimental Analysis of Behavior, 89, 15-30.

Greer, R. D., Singer-Dudek, J., Delgado, J. P., \& Oblak, M. (2007, March). Books as a conditioned reinforcer for performance and acquisition tasks as a function of observation. Presented as part of a symposium entitled, Observational conditioning. Paper presented at the $2^{\text {nd }}$ annual international CABAS ${ }^{\circledR}$ conference, Suffern, NY.

Greer, R. D., Singer-Dudek, J., \& Gautreaux, G. (2006). Observational learning. International Journal of Psychology, 41(6), 486-499.

Greer, R. D., Singer-Dudek, J., Longano, J., \& Zrinzo, M. (in press). The emergence of praise as conditioned reinforcement as a function of observation in preschool and school age children. Revista Psychologie Mexico. 
Griffen, A. K., Wolery, M., \& Schuster, J. W. (1992). Triadic instruction of chained food preparation responses: Acquisition and observational learning. Journal of Applied Behavior Analysis, 25, 193-204.

Kazdin, A. E. (1973). The effect of vicarious reinforcement on attentive behavior in the classroom. Journal of Applied Behavior Analysis, 6, 71-78.

Kelleher, R. T. \& Gollub, L. R. (1962). A review of positive conditioned reinforcement. Journal of the Experimental Analysis of Behavior, 5(4), 543-597.

McDonald, R. P. F., Dixon, L. S., \& Leblanc, J. M. (1986). Stimulus class formation following observational learning. Analysis and Intervention in Developmental Disabilities, 6, 73-87.

Nuzzolo-Gomez, R., Leonard, M. A., Ortiz, E., Rivera, C. M., \& Greer, R. D. (2002). Teaching children with autism to prefer books or toys over stereotypy or passivity. Journal of Positive Behavior Interventions, 4, 80-87.

Ollendick, T. H., Dailey, D., \& Shapiro, E. S. (1983). Vicarious reinforcement: Expected and unexpected results. Journal of Applied Behavior Analysis, 16, 485-491.

O'Rourke, C.A. (2006). Conditioning math as a reinforcer for performance and learning as a function of observation. (Doctoral Dissertation, Columbia University). UMI Proquest Digital Dissertation [on-line]. Dissertations Abstracts Item: AAT 3213574.

Tsai, H. H. \& Greer, R. D. (2006). Conditioned preference for books and faster acquisition of textual responses by preschool children. Journal of Early and Intensive Behavioral Interventions, 3(1), 35-60.

Werts, M. G., Caldwell, M. K., \& Wolery, M. (1996). Peer modeling of response chains: Observational learning by students with disabilities. Journal of Applied Behavior Analysis, 29, 53-66.

Correspondence regarding this study should be sent to the first author.

Jessica Singer-Dudek

Box 223

Teachers College, Columbia University

525 West $120^{\text {th }}$ Street

New York, NY 10027

E-mail: js408@columbia.edu

R. Douglas Greer

Box 76

Teachers College, Columbia University

525 West $120^{\text {th }}$ Street

New York, NY 10027

E-mail: greer@exchange.tc.columbia.edu

Jeannine Schmelzkopf

E-mail: jean9s@aol.com 